\title{
English Language Learning in the Malaysian School Setting: Where Can We Find 10,000 Hours? A Theoretical Perspective
}

\author{
George Iber \\ University of Evansville, USA \\ E-mail: gi17@evansville.edu
}

Doi:10.7575/aiac.alls.v.7n.4p.46

URL: http://dx.doi.org/10.7575/aiac.alls.v.7n.4p.46
Received: 02/03/2016

Accepted: 06/05/2016

\begin{abstract}
In these days of standardized assessments in education that seek to measure the rate of learning in all subject matters, the question is seldom asked, "Just how long does it take to become proficient?" No matter the subject, we all agree that some amount of practice is necessary for basic proficiency and that more will be needed to really master a skill or subject area. But how much is difficult to say because different individuals come to the task with different levels of motivation and opportunity to learn. In the case of learning a second or foreign language different theories predict that a two to five year "structured exposure" is needed for either a basic communication or an academic level of proficiency (Cummins, 1980) respectively. This paper proposes that the range can be described in terms of hours. Based on the concept from Outliers by Gladwell (2008), this paper proposes that 10,000 hours is the target "time-on-task" required for academic proficiency in second language learning. The implications for school language study is readily apparent. If we want academically proficient second language speakers, those individuals will need to have access to the target language in numbers vastly greater than school can provide in its standard curriculum.
\end{abstract}

Keywords: Second language learning, curriculum development, foreign language learning, time-on-task, international education, exchange programs, English as a foreign language

\section{Introduction}

There is a great deal of discussion, and has been ever since modern schools were designed about a century ago, about the place of learning a foreign language in the curriculum. The general importance of a multilingual individuals likely dates back to our tribal ancestors when they traveled away from their villages to encounter other tribes. Strange it must have seemed for them to encounter peoples identical in every from except for the language they spoke. Stranger still if these other peoples were engage in a serious attempt to capture these foreign sounds and concepts onto clay tablets, bark, papyrus, or knotted strings. So far back does the origin of our Indo-European family of languages extend that there is little known about the location or the culture of the ancient people. Without a specific documented history, the art of writing, developed circa 3500 B.C. (Campbell, 1968) has always been accompanied by myth, whether in the telling of stories or the stories of its origin.

Without doubt the higher status of diplomats, government officials, scholars, and individuals of influence is gained in part by the signature requirement of having literate capacity in at least two languages. Today the argument about multilanguage use and cultivation is clearly front page news. The New Straits Times, (2016) recently ran an article advocating the learning of English was crucial for young students to avoid underemployment (On the path to proficiency, October, 2015). Further, the Malaysian Blueprint (2013-2025) has created a goal for all students to master at least two languages in an academic setting, Bahasa Malaysia and English, with an addition of a third, often vernacular language such as Mandarin as a third language. Such is the state of Malaysian language policy today. One can discuss many different aspects and advantages of implementing vernacular schools, improving teacher language credentials, requiring English to enter University, the need for a national language policy, or the practicalities of international language usage, all are a part of the debates within the global educational world. What isn't discussed is how to achieve these goals within the school system itself.

\section{Background}

The Malaysian Blueprint (2013-2025) clearly outlines a path for improving six areas of student outcomes, including Bilingual language abilities English and BM language abilities (2-5). The roadmap to accomplishing 1119 assessment success by all ethnic groups in Malaysia is an ambitious and commendable goal for curriculum design. Nevertheless it also points out that a large percentage, between 20 and 50\% fail to achieve a passing English grade (Exhibit 3-19). To improve the outcomes, the Ministry has suggested three waves of changes to the curriculum and school culture. Of note, it stresses a curriculum that is "Written, Taught, and Examined" (Exhibit 4-1). The Blueprint advocates many excellent steps for improving teachers, schools, and student outcomes over time.

The written, taught, and examined curriculum can be viewed as the formal school curriculum. Formal school learning however is not the only element of student success. I propose that formal curriculums alone are often insufficient to 
ensure student success in complex areas of learning, including language achievement. However, there is an additional important curriculum that is equally as important, sometimes designated as the "hidden" curriculum, I prefer to call it the cultural value curriculum. Krashen (1982) famously proposed the hypothesis that language achievement was "acquired" rather than "learned." True language mastery is a sub-conscious achievement, as any young child makes evident. On the other hand, language learning is a formalized school oriented achievement, something measurable, for example on spelling examinations, whereas language acquisition is the result of interaction and exposure to language phenomena. For academic language achievement, as measured by 1119 for example, both are necessary. Advanced language is accomplished in a meaningful interactive context, i.e. comprehensible input.

\section{Theoretical perspective}

Jim Cummins (1979) first discussed the difference between common everyday language attainment, which he labeled "Basic Interpersonal Communication Skills" or BICS, and Cognitive Academic Language Proficiency, or CALP. There are two critical factors involved in moving from BICS to CALP: time and schooling. With respect to time, BICS can be acquired in about two years in a "language rich" environment, while CAPL requires the structured exposure to academic level material and can be attained in 5 to 8 years, depending upon the grade level. The latter is what we refer to as academic English, it is learned. These learning estimates are based on learning English in a language context like Canada or the United States. A context with daily support and necessity to master the language.

Another perspective on the need for adequate time to learn complex tasks comes from Malcom Gladwell's (2008) book, Outliers: The story of success. Outliers are defined as successful individuals who demonstrate a statistical difference from the norm in talent and achievement. What he discovers is that while there are individuals of talent and high motivation, even these individuals must have a strong support system and sufficient time. He devotes a chapter to his benchmark figure of 10,000 hours. He proposes that the 10,000 hour rule can apply to musicians, computer programmers, even sports stars; somewhere somehow all successful individuals had the opportunity to get the practice necessary for success. Interestingly the 10,000 hour rule fits closely to Cummin's (1979) estimate for BICS language proficiency of 2 to 3 years. If 10,000 hours are divided by 16 hours (a full waking day), it equals 625 days, or approximately two full immersion years of language exposure.

\section{Extrapolation of time required for BICS proficiency}

\section{- Cummins suggests a 2-3 year threshold to BICS proficiency \\ - Ideal conditions would equate to 365 days @ 16 hours per day, or $\mathbf{5 8 4 0}$ hours per year \\ - School only time is at best 205 days @ 7 hours per day, or 1435 hours \\ - English class alone is only 205 hours per year.}

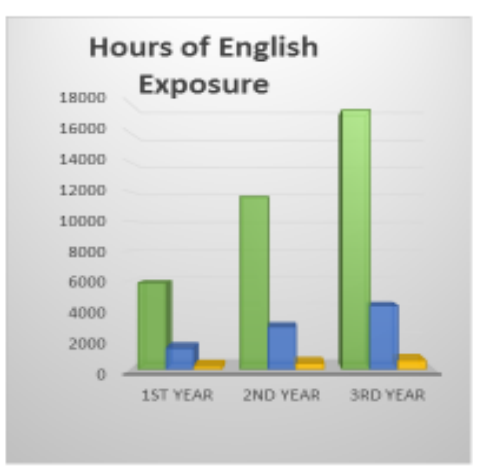

The Blueprint (2012) points out that the typical Malaysian student lives 27\% of his waking time in school (Exhibit 2-2). However that statistic is misleading. One tends to think of schooling as a total block of experience when in reality it is very segmented. Each day of school is divided into different subject areas. Based on a school year of 210 days, the total school classroom time allocated for English instruction as 45 minutes per day, which amounts to only 157 hours per year. Assuming one is awake for 16 hours per day, the total instruction time for English only amounts to 9.8 days! Just 9.8 days per year is the total instruction allocated per year in a school setting. A more realistic estimate of engaged classroom time might cut the engaged time in half! What are the implications of this amount of time available for learning another language? By comparison, an L1 speaker of language in his own country will have 365 days of language practice. Thus a native speaker in an L1 language context has 37 times more practice time than a school only learner. The inputs are not nearly equal. Is it any wonder so many are discouraged at their rate of learning another language in school? Comparing this number with the 10,000 hour rule, we find that typical school only exposure is at best about 9 days per year; at that rate it would take the equivalent of 69 years to achieve the same proficiency that is accomplished in two years in a structured immersion context! That is a great deal of "time-on-task!"

Now, let's review the English language situation in Malaysia. While posted at the ELTC in Malaysia as an English Language Fellow, I proposed that Malaysia has all three cohorts of English language users (Iber, 2014). The full Kachru model applies to Malaysia, not just the ESL band. In other words, Malaysian students of English come from all three distinct language background orientations. 


\section{Malaysian school setting}

No one will deny that Malaysia has a rich language heritage. Modern and ancient languages have mixed for centuries and created unique blends. In addition two of the most widely spoken languages on the planet are part of Malaysia's modern heritage: Mandarin Chinese and English. Tamil and Malay are geographically concentrated locally. As a result, children growing up in Malaysia have a broad exposure to multiple languages but because English is neither an official language nor a school language, students enter the school system with vastly different exposure time to English.

Kachru's model of English language use distribution.

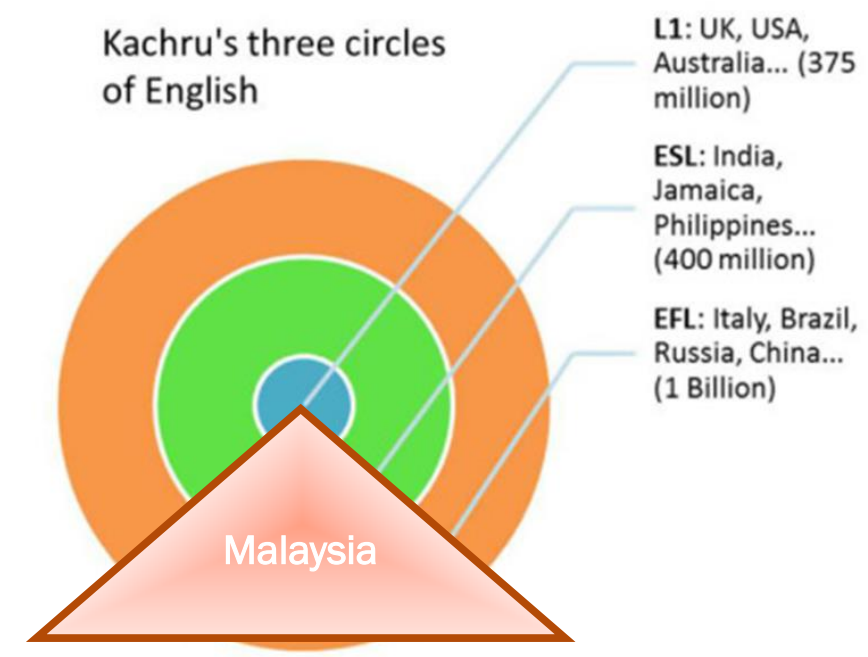

The reality of English language learners in Malaysia is that they occupy all three bands of Kachru's model. There are those who speak English as their L1 language, there is a broad second group that is exposed to a high frequency of English in the schools and the urban environments such as Kuala Lumpur to be classified as ESL learners. But there is a significant third group that for reasons of immigration, geographic location, history, socio-economic standing, poor experience in school, can be categorized as English as foreign language learners. For these students English is third or fourth language that they are trying to dominate. These students may very well be talented multi-lingual speakers, but English remains a foreign language to them from a teaching point of view (Iber, 2014).

According to the Blueprint (Exhibit 4-6) (2012) only 28\% of SPM students achieve Cambridge 1119 minimum proficiency in English. This figure presents a large aspirational goal for the 2025 of $70 \%$. The Blueprint places an incorrect blame for this result on the teachers of English. Although teachers may be a part of the solution, the primary factor in the poor English language results is the lack of time, exposure, and use of English by the students. It is interesting to note that according to the United Nations (2014), $74 \%$ of the Malaysian population lives in urban areas, thus the often cited urban/rural divide is not the basis of the variance in English language skills.

Why are $28 \%$ of the students successful in obtaining academic English proficiency and others not? They receive additional hours of practice opportunity outside of school. This comes in the form of support from the home and community in which they live. This translates into a strong aspirations to learn an additional language due to a clear reason for mastering the subject. A study by Onwuegbizie (2000) discussed the factors that correlate with successful foreign language learning. The study indicated that the best predictor of foreign language success was the student's overall academic achievement in school. In other words the better the student the more likely that student will success in second language achievement. It was noted that lower reading ability in the native language brings with it a number of deficits that influence the foreign language learner. The better student tends to have more interest in maintain that status and will put more time into achieving language proficiency, conversely a student with a low level of expectations will not.

\section{Observations as English Language Fellow in Malaysia (2013-2014)}

While working in Malaysia as a Senior English Language Fellow in 2013-2014, I was posted to the English Language Training Centre. There, my team and I were tasked with developing a series of modules under the title of Remedial Instruction. The term, remedial instruction, is used in a peculiar way in this context. The term "remedial" did not refer to students of limited learning capacities, but rather simply instructional strategies designed for students who were considered "as risk" of not being able to complete the then proposed 2016 "Must-Pass" exam for English. The modules focused on interactive strategies that would be more engaging for students, thus, the reasoning was, the students would be in a better position meet whatever standardized assessment were designed. What I quickly came to observe however was a disconnect between the existing English curriculum, the general pace and scope of actual English teaching in the classrooms, and the proposed English Must-Pass requirement.

Learning a second language well requires long term motivation. In addition there must be qualified teachers and sufficient time. Based on what I observed in the various classrooms, neither the students nor the teachers would ever meet the goals. Certainly those working at ELTC represented the pinnacle of English language ability in Malaysia, but 
it seemed an island within a sea of plantation coconut palms. No taxi drivers knew where it was located, only by asking to be taken to Kampung LBJ were we able to arrive from Seremban. Since no cafeteria was available at ELTC we generally ate nearby. Frequently we ate lunch at the "car wash" where tasty Indian food was always served. But the quest in the back of my mind was always to find out who and where English was spoken. The car wash announced, in a big sign, "snow wash" which I found confusing for a climate that is regularly 90 degrees. The TV at the tin roofed restaurant blared Tamil language Indian music and dancing videos. My wonderful hosts had to switch from English to Tamil to communicate, but we had excellent curry and dhal dishes. When we tired of Indian food we went a few yards up the road to the Chinese restaurant. There we could order nasi goring, nadi lemak, noodles and kopi, but not in English. Further down the road my Muslim teammate took us sometimes to an halal restaurant. Kopi, always available, combined wonderfully with rambutan fruit with ikan bakar. Always fine tastes, but seldom in English.

To continue the restaurant metaphor from above, the Malaysian schools I visited proved similar in some ways. There are Indian schools, Chinese schools, and Malay schools. In all of them I saw dedicated administrators, teachers, and good students. These were precious opportunities to see where the remedial program for English might be deployed. I left with doubts that the remedial program modules would have a lasting impact on the students. There was simply no obvious reason for many of the students to learn English. In some cases they had never used English outside the classroom, for these young students the experience of English was confined to worksheets and grammar instruction. How would they more actively interact with the modules we were developing? Certainly I did not visit all schools, but based on this sampling we concluded that the "upscaling" of teachers would be a long term prospect and that the current curriculum map for English needed to be revised. It was here that the Kachu model took on a meaningful new dimension. I concluded that Malaysia was not a second tier ESL country, based on the Kachru model, but rather it is a multi-tiered country that would require a multi-tiered curriculum approach. The most shocking statement that I made was to suggest that Malaysia need to have three English language curriculums, or at least three categories of assessment, including English as a foreign language. One curriculum for those to whom English is a life and daily functioning language. A second curriculum for those who have the potential to use English in the future, in careers of tourism, engineering, or other professions that require a high English language function. Finally a third tier, and this was the most radical proposal, a new curriculum that treats English as a foreign language. The language reality in Malaysia is that for many children, adults, and communities English is a foreign language. Knowing a few dozen words of another language does not qualify a person to claim ESL status. According to UNESCO information and Ethnoloque (2015), more than 140 languages can be found within the boundaries of Malaysia, and of course that count does not include languages spoken by the thousands of tourists that visit every year. Malaysia must embrace its multi-linguistic heritage, there is no other option. English is a specialized language in Malaysia due to historical ties to Great Britain and the modern world's use of English as a lengua franca, but it cannot be a language learned evenly or mastered by a majority of the population in the near future. Of course, all students can learn some English.

\section{Policy Implications}

Because Malaysia has three bands of English learners, three different approaches to English leaning in school must be considered. Whether it is three separate curriculums or three versions on one curriculum is not the most important factor. I have argued that the most important factor is time to engage in meaningful practice. Without significant time to master a second language a school only program will produce differentiated results. The inputs for all students are not the same. To have a successful second (or third) language program requires assurance that students:

1. Establish a strong academic foundation in students' first language.

2. Develop a student survey that establishes a student's language profile.

3. Have multiple entry points for learning the second language.

4. Design a curriculum(s) that rewards student learning at all levels of language learning.

5. Sufficiently train teachers to work in a differentiated language classroom.

6. Provide much more time within the traditional school year for the necessary comprehensible input necessary for successful language outcomes.

7. Establish opportunity options for structured language immersion experiences.

8. Have multiple levels of exit criteria that recognizes success on both the BICS and CALP level.

With a program design that contains these elements, all students will have the ability to succeed, although not all will achieve 1119 or CEFR native fluency, nor should that be expected. It must be recognized that true academic bilingual or trilingual individuals represent a talented elite cultural resource.

Whether we use Cummins (1979) or Gladwell (2008) as our theoretical estimate for learning a second language, those who do achieve native like fluency are highly motivated and have the time for learning, and as this paper proposes, that will be about 10,000 hours of comprehensible input. A research study by Davidson (2007, 2010) noted strong correlations between learning achievement and mastery in Russian and the length of structured immersion study abroad programs in Russia. Sasaki (2007) showed the benefits of study abroad Japanese students learning English composition compared to "stay at home" students learning English. In both theory and practice, time is crucial, and time may come from home situations, private tutors, select study abroad programs, or even friends and the community where the 
student has time to interact. The guidance in formal language structures usually will be found in the school setting. Together, the school and the student's ability to meaningfully interact for an extended period of time is the formula for success in learning a language well. School based assessments should reflect that formula.

Students with only school classroom time to learn will achieve at a vastly different level but their achievements can be recognized as "passing." They have passed a school base language program much like any other foreign language. School programs provide a foundation for more practice and training in later life. The students who are fortunate enough to have additional learning opportunities to practice and master an additional language will excel at higher levels and can be assessed differently and recognized accordingly.

\section{References}

Cummins, J. (1980). The construct of language proficiency in bilingual education. In Georgetown University Roundtable on Language and Linguistics 1980. Edited by James E. Alatis. Washington DC: Georgetown University Press. P. $81-103$.

Davidson, D. E.. (2007). Study Abroad and Outcomes Measurements: The Case of Russian. The Modern Language Journal, 91(2), 276-280. Retrieved from http://www.jstor.org/stable/4626014

Davidson, D. E. (2010), Study Abroad: When, How Long, and With What Results? New Data From the Russian Front. Foreign Language Annals, 43: 6-26. doi: 10.1111/j.1944-9720.2010.01057.x

Gladwell, M. 2008. Outliers: The story of success. Little, Brown and Company, New York.

Iber, George L. (2014). Iber, G. (2014). English language teaching in Malaysia: The case for a dual track English curriculum [Short Communication]. Advances In Language And Literary Studies, 5(4), 68-71. Retrieved fromhttp://www.journals.aiac.org.au/index.php/alls/article/view/428/366 Australia.

Kachru, B. (1990) The alchemy of English: the spread, functions, and models of non-native Englishes, University of Illinois Press.

Krashen, S. (1982). Krashen, S. 1978. The monitor model for second-language acquisition. In: Second-language acquisition and foreign language teaching. Edited by R. C. Gingras. Arlington,Va.: Center for Applied Linguistics

Lewis, M. Paul, Gary F. Simons, and Charles D. Fenning (eds) (2015). Ethnologue: Languages of the World, $18^{\text {th }}$ ed. Dallas, Texas: SIL International. Online version: www.ethnologue.com

Malaysia Education Blueprint 2013 - 2025. (2012). Ministry of Education, Malaysia.

New Straies Times. (2016) Unemployed because they can't speak English. Retrieved February 15, 2016: Malaysia. http://www.nst.com.my/news/2016/02/125529/unemployed-because-they-cant- speak-english

Onwuegbizie, A., Bailey, P., \& Daley, C. (2000) Cognitive, affective, personality, and demographic predictors of foreign-language achievement, The Journal of Educational Research, 94, 3-15.

Sasaki, M. (2007). Effects of Study-Abroad Experiences on EFL Writers: A Multiple-Data Analysis. The Modern Language Journal, 91(4), 602-620. Retrieved from http://www.jstor.org/stable/4626088

United Nations, Department of Economic and Social Affairs, Population Division (2014). World Urbanization Prospects: The 2014 Revision. Table A-1, p 198. 